\title{
Digital Skills Scenario of the Workforce to Promote Digital Economy in Thailand under \& Post COVID19 Pandemic
}

\author{
Kamolrat Intaratat \\ Associate Professor-School of Communication Arts, Sukhothai Thammathirat Open University, Thailand
}

\begin{abstract}
Thailand's Digital Skills Scenario of the Workforce to Promote Digital Economy Under \& Post COVID-19 Pandemic is a qualitative research that involve an e-interview and desk research focused on the ecosystem of workforces empowerment in Thailand relevant to digital skills to serve the digital economy. The e-Interviews have been made to 45 interviewees who are urban migrant job seekers, fresh graduated students, private sectors, business associations, and government agencies under the current situation where COVID-19 pandemic and the technologies disruption to shape the new future jobs. Its objectives are to study 1) the scenario of workforces under the digital economy affected from COVID-19 pandemic and the technology disruption relevant with digital skills in Thailand; 2) the scenario of the digital skills relevant to the future jobs skills among all the workforces in Thailand; and 3) the government's policy relevant digital re-skill-up-skilling among the workforces for the current demanding jobs and post COVID-19.
\end{abstract}

Findings are 1) the scenario of workforces relevant with digital literacy and digital skills among all the marginal workers from selected ASEAN countries found affected by the pandemic as well as technology disruption resulted in a pattern of businesses shifting from the formal sector to the informal sectors that affected to most of the low-mid skilled. The future of work has already arrived for a large majority of the online whitecollar workforce. eighty-four percent of employers are set to rapidly digitalized working processes, including a significant expansion of remote work with its trend to change, currently $44 \%$ of workforces operates remotely; 2) the scenario of the digital literacy and digital skills relevant to the current and the future jobs skills among all the marginal workers found the top emerging jobs are data analysts, data scientists, digital marketing specialist, software and application developer, youtubers and start-ups. All kinds of administrative jobs, secretaries, accounting, book keeping, payroll clerk, HR would be declining. Most of the marginal workers have low -mid digital skills such as Microsoft Office, digital marketing, photoshop, social media, content creating, video editing. Workers are looking forward to re-skills in all related digital skills ranking from fundamental to mid and high skills such as data analytic, data science, software development, web development, cybersecurity, AI and programing which concerned as a necessary profile that one must have in-depth knowledge in order to attract all the demanding jobs; and 3) the government's policy relevant to support any digital re-skill, up-skilling among all the workforces including the marginal workers to serve well with all demanding skills of the future jobs found similar in 1) accelerate workforce digital competency by partnering with private and industry sectors through TVET training system; 2) working with industry leaders to revamp national curriculums via digital learning pathways and emerging skillsets. The PPP strategy must be used for knowledge transfer and support to building Digital Ecosystem.

Keywords: digital skills, digital economy, Thai workforces, COVID-19 pandemic

\section{INTRODUCTION}

$\mathrm{T}$ hailand is working to drive digital transformation and utilize innovation to become a cutting-edge economic powerhouse. The country's digitization journey begins with the "Thailand 4.0" economic model which concentrates on important advancements and digital improvements to enhance the quality of life, productivity and efficiency of the Thai people. The Digital Economy is expected to play a critical role in every industrial sector in Thailand and is estimated to contribute $25 \%$ to Thailand's GDP by 2027 (Ministry of DES, Thailand, 2019).

While under the global and regional pandemic of COVID-19 besides from all kinds of disruptive technologies and innovations demanding affected to all recession globally and regionally since 2019 till currently. In 2020, the tangible effects seen in the labor market and accelerated the arrival of the future of work from its pandemic-related disruptions and the technology adoption relevant in jobs and skills in the next five years despite the currently high degree of uncertainty by its nature and challenges. Thailand also got its hard hit and impact along with other countries in Southeast Asia (ASEAN) as well as other countries beyond ASEAN (the Future of Jobs Report 2020).

Under the midst of regional and global recession brought on by the COVID-19 pandemic and technology disruption affected millions of workers especially among all the marginalizes whom lack of digital literacy and skills for all disruption. A shortage of new digital skill-based workers is one of the biggest challenges in Thailand like the other neighboring countries in ASEAN due to the ASEAN Economic Community (AEC) which connected among all the members countries aims for its significantly expand investment, collaboration as well as competition in the region along the global economic expansion too. 
Thailand's Digital Economy has a profound impact on both the business landscape and the lives of people especially among all the marginalizes. At the global phenomenal, the number of internet users has grown exponentially due to a number of significant technological advancements. Thailand and other ASEAN member countries is no exception to this phenomenal. ASEAN has been regarded as one among the world's fastest growing internet region, while ASEAN's digital economy has also been predicted to reach a value of USD 2 trillion by 2025 . With its market value of its digital economy considered to be the 2 nd largest in ASEAN, Thailand has witnessed a digital revolution affecting processes, activities and transactions across almost every sectors. Driven by the pursuit of the economic targets and vision contained within its Thailand 4.0 policy: Smart Thailand to walk on its way to achieving digital transformation. In 2018, it was estimated that approximately $17 \%$ of Thailand's Gross Domestic Product (GDP) was derived from its digital economy.

However, whether Thailand could claim its successfully achieve in digital economy as well as its abilities to equip their workforce with general and job-specific skills needed by the growth industries they are promoting. So, this research explores the scenario of digital skills among all workforces relevant with digital literacy and skills among all the marginal workers whom affected especially the ones who lack of economic opportunity due to their lack of digital literacy and skills under the pandemic of COVID-19 and technology disruption. The benefits from this study aims to be used for its planning to prepare all workforces especially the marginal workers in the demanding future of jobs and skills related to digital literacy and skills as well as all relevant contexts in Thailand i.e. the related government policies, and public-private partnership under the COVID-19 pandemic and digital technologies disruption.

\section{LITERATURE REVIEW}

The COVID-19 pandemic induced lockdowns and related global recession of 2020 have created a highly uncertain outlook for the labor market and accelerated the arrival of the future of work. The Future of Jobs Report 2020 aims to shed light on: 1) the pandemic-related disruptions thus far in 2020, contextualized within a longer history of economic cycles, and 2) the expected outlook for technology adoption jobs and skills in the next five years. Despite the currently high degree of uncertainty, the report uses a unique combination of qualitative and quantitative intelligence to expand the knowledge base about the future of jobs and skills. It aggregates the views of business leaders : chief executives, chief strategy officers and chief human resources officers whom are the frontlines of decision-making regarding human capital empowerment to create a fit way and strategy to prepare all workforces for all the demands of future jobs and skills.

In 2020, economic globalization is stalling, social cohesion is being eroded by significant unrest and political polarization, and an unfolding recession is threatening the livelihoods of those at the lower end of the income spectrum. As a new global recession brought on by the COVID-19 pandemic impacts economies and labor markets, millions of workers have affected which have profoundly transformed their lives within and beyond, their income, their productivity and their quality of lives. Because of the Lack of economic opportunity from lacking of all relevant digital technology and digital tech-enabled knowledge and skills to achieve highwage, high-growth jobs especially all the job in the future which require digital fluency. Workforces from the underserved communities are consistently underrepresented in the scene of digital technology and innovation. COVID-19, economic recession, digital disruption and transformation have expanded and deepened all kinds of digital divide; the negative impact existed and still going on globally.

In late 2019, the gradual onset of the future of work due in large part to automation, technology and globalization appeared to pose the greatest risk to labor market stability, significant and unexpected disruption to labor markets, with immediate knock-on effects on the marginalized workers besides the COVID-19 pandemic appears to be deepening all difficulties across labor markets. The changes heralded by the COVID-19 pandemic have compounded the long-term changes already triggered by the Fourth Industrial Revolution, which has consequently, increased in velocity and depth. Figure 1 shows the employment trends of jobs in the United States at high risk of automation, 2007-2018 (the Future of Jobs Report 2020). (Figure 1) 


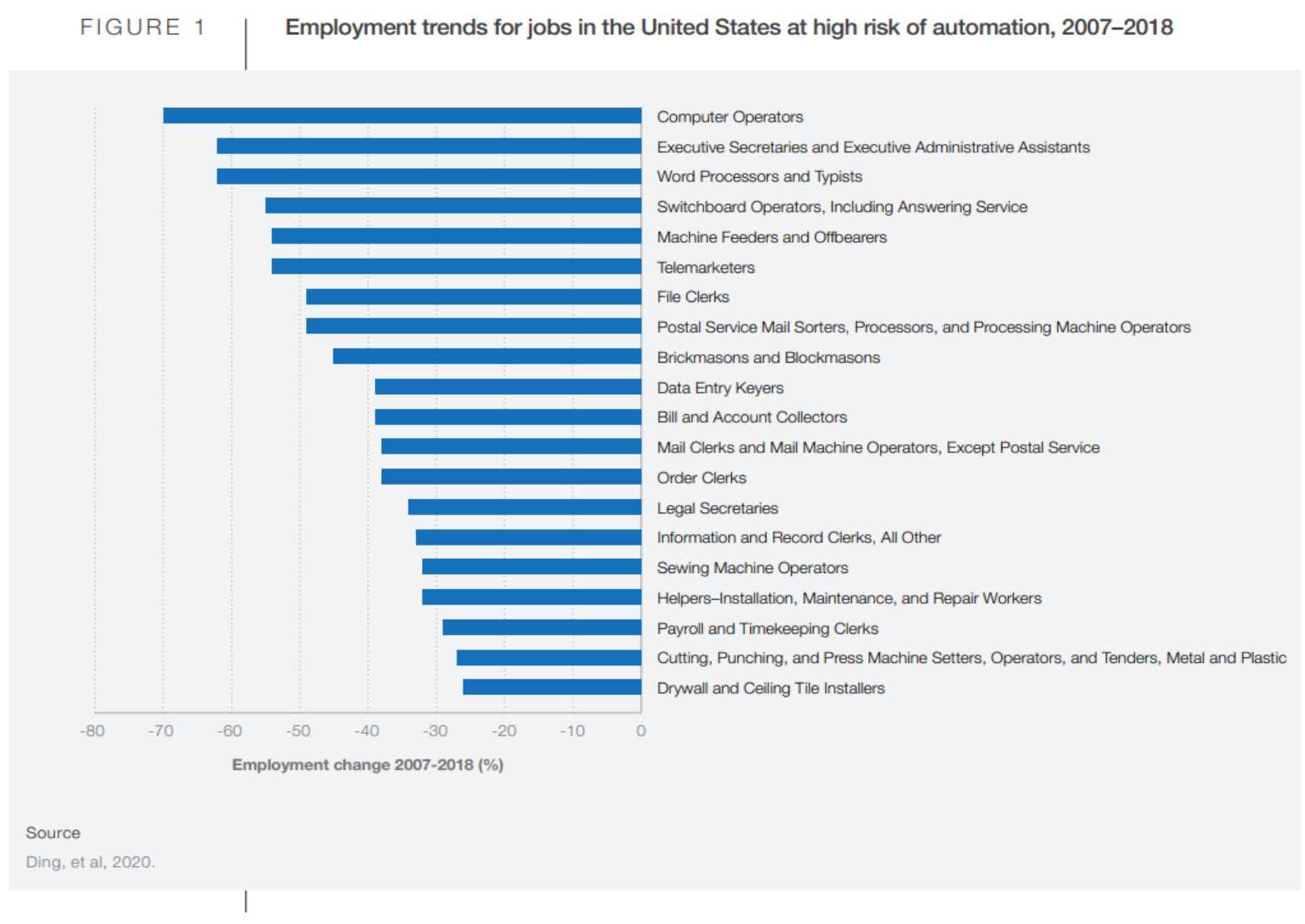

Figure 1: The employment trends of jobs in the United States at high risk of automation, 2007-2018 (the Future of Jobs Report, 2020)

Technology disruption keeps expanding and affected in most of the job areas i.e. Cloud computing, Big data, ecommerce and also some of a significant rise in interest for encryption, non-humanoid robots and AI : Artificial Intelligence. By 2025, tasks at work by humans and machines will be equal. A significant share of companies also expect to make changes to locations, value chains, and the size of workforce due to digital technology and innovation. Number of jobs destroyed will be surpassed by the number of 'jobs of tomorrow' created by 2025,85 million jobs may be displaced by a shift in the division of labor between humans and machines, while 97 million new jobs may emerge more adapted to the new division of labor between humans, machines and algorithms. Digital skills gaps continue to be high as well as some of the emerging demands of soft skills such as critical thinking and analysis, problem-solving, selfmanagement such as active learning, resilience, stress tolerance and flexibility.

\section{Thailand's Digital Competitiveness Scenario}

Since Thailand's creation of the Digital Economy and Society Development Plan in 2016, a number of positive strides have been taken towards achieving improved economic and social development. These developments have been captured across a range of different international rankings and indices as shown in Figure 1.
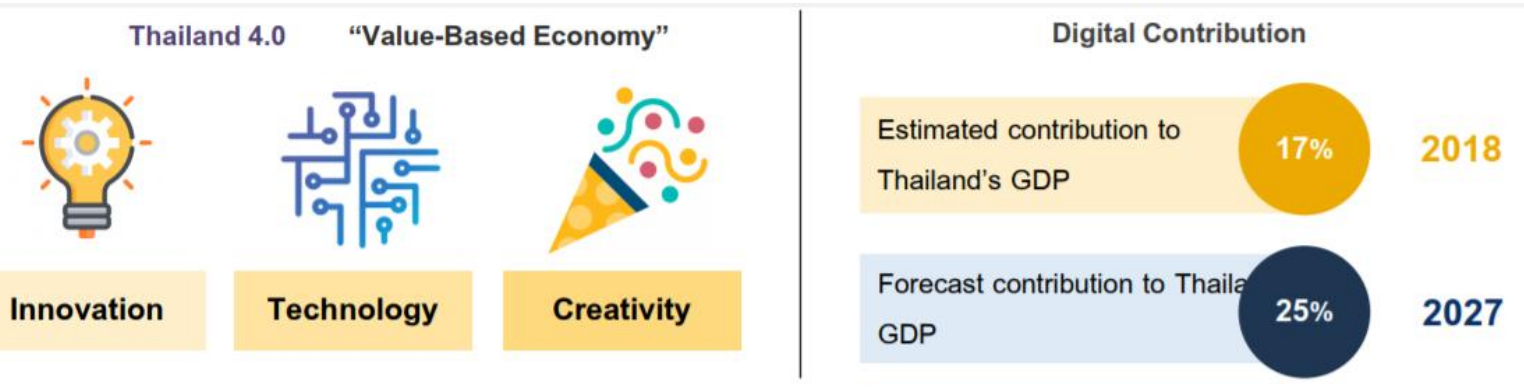

Figure 1 Thailand's Digital Competitiveness Scenario, Ministry of DES, Thailand, 2019 
As part of the country's drive towards achieving an economy that is propelled by digital and cutting-edge technologies, numerous steps have been taken to improve overall efficiency and economic growth. This approach has

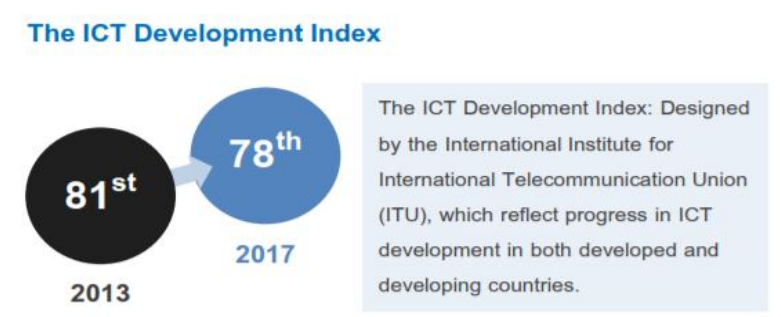

seen Thailand stand out as a digital leader within ASEAN, and is reflected in the country's improvements across a range of international rankings as shown in Figure 2.

World Digital Competitiveness Index

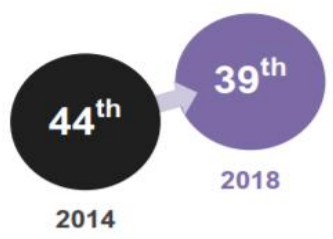

World Digital Competitiveness Index: Published by the International Institute for Management Development (IMD), this ranking determines countries' levels of digital competitiveness as scored against 50 indicators.

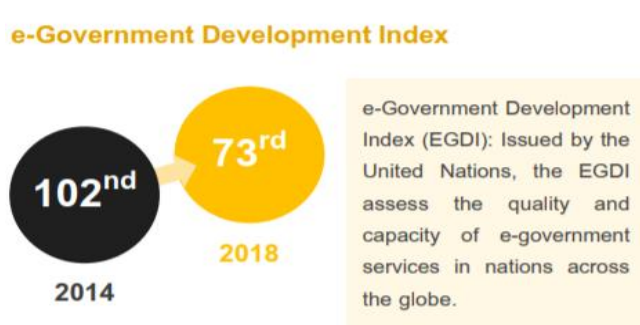

2014 the globe.
World Competitiveness Ranking (Technology Infrastructure)

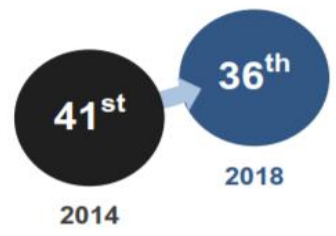

World Competitiveness Ranking (WCR): Launched by the International Institute for Management Development (IMD), the WCR measures the institutions, policies, and factors affecting the levels of economic prosperity. In 2018. Thailand improved significantly in technology infrastructure, jumping form $41^{\text {st }}$ 2014 , to $36^{\text {th }}$ in 2018

Figure 2 Thailand's Digital Competitiveness Scenario among the Globe, Ministry of DES, Thailand, 2019

Jobs held by marginal workers, women and youths were more deeply impacted in the first phase of the economic contraction. Comparing the impact of the Global Financial Crisis of 2008 on individuals with lower education levels to the impact of the COVID-19 crisis, the impact today is far more significant and more likely to deepen existing inequalities. The re-skill and up-skill become shorter in the newly constrained labor market. A significant number of business leaders understand that reskilling employees, particularly in industry coalitions and in public-private collaborations, is both cost-effective and has significant midto long-term dividends not only for their enterprise but also for the benefit of society more broadly while the public sector needs to provide stronger support for re-skilling and upskilling for the at-risk or displaced workers. Currently, only $21 \%$ of businesses report being able to make use of public funds to support their employees through re-skilling and upskilling. The public sector will need to create incentives for investments in the markets and jobs of tomorrow; provide stronger safety nets for displaced workers in the midst of job transitions; and to decisively improve education and training systems. Additionally by the governments longer-term policy about labor market and serving real demanding jobs (the Future of Jobs Report 2020).

\section{Thailand's Workforces Relevant in Digital Skills}

Thailand provides the necessary social and economic factors required for a strong and vibrant digital economy. These include human resources, digital infrastructure and supportive government policies.

Thailand's labor force has played a significant role in transforming the country into a digital economy. This progress has been fundamentally driven by a consistent stream of university graduates in a range of fields related to ICT. In 2018, there were approximately 31,000 people working in ICT-related fields in Thailand as shown in Figure 3.

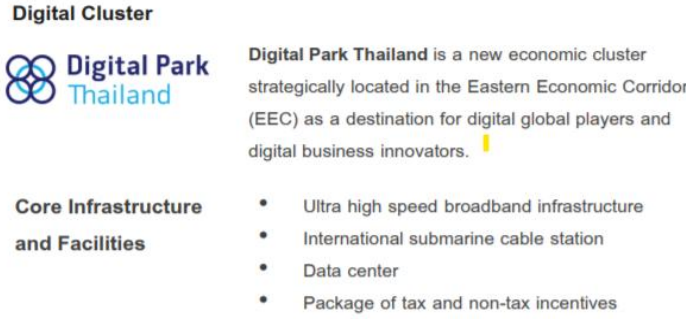

Figure 3 Thailand's Digital Workforce Development Scenario, Ministry of DES, Thailand, 2019 


\section{Thailand's Startup Ecosystem}

Thailand's vibrant startup ecosystem is largely attributed to the availability of strong partnerships with creative companies, groundbreaking ICT entrepreneurs, and high customer demand. From 2012 to 2017, the number of startups funded by venture capital in Thailand increased from a mere 3 in 2012, to more than 90 companies in 2017. Funding for startups over the same period also increased at a rapid rate from 2.1 million USD in 2012 to 271.48 million USD in 2017.

The country provides a robust, well-functioning, and well-structured ecosystem to support various startup initiatives, ranging from venture investors, accelerators, and incubators, to government agencies and private firms as shown in Figure 4.

\section{Thailand Startup Ecosystem Development ${ }^{1}$}

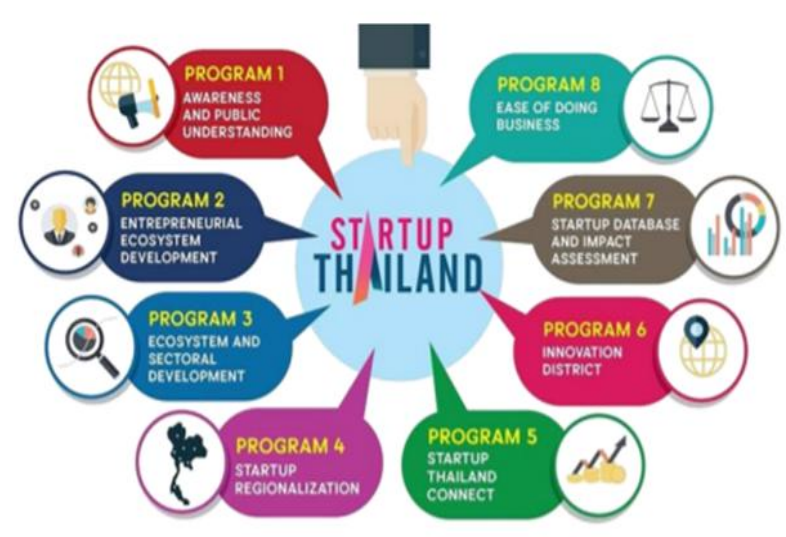

Figure 4 Thailand's Startup Ecosystem Scenario, Ministry of DES, 2019

To drive genuine transformation and develop a digital infrastructure to serve all workforces for country development with easily accessible, notable investment has been made across a range of areas. For hard infrastructure, the government has put emphasis on providing internet speed, internet connection, as well as the connection of submarine cables and clusters for digital industry. Besides in the past few years, Thai government has launched various new laws and regulations to support the implementation of its digital economy policy. Legal updates also include the Act on Digital Development for Economy and Society, which saw the establishment of the National Digital Economy and Society Committee chaired by the Prime Minister. The purpose of these new laws and regulations is to enhance convenience, reduce obstacles, and increase efficiency in online activities and transactions such as the Electronic Transactions Act, the Computer Crime Act, the Digital Development for Economy and Society Act, the Data Privacy Act, the National Cyber Security Act, and others.

\section{Research Objectives}

Thailand's Digital Skills Scenario of the Workforce to Promote Digital Economy Under \& Post COVID-19 Pandemic has its objectives under the context of COVID-19 pandemic and digital technology disruption as follow;

1. To study the scenario of workforces under the digital economy affected from COVID-19 pandemic and the technology disruption relevant with digital skills in Thailand;

2. To study the scenario of the digital skills relevant to the future jobs skills among all the workforces in Thailand;

3. To study the government's policy relevant digital reskill and up-skilling among the workforces for the demanding future jobs and post COVID-19.

\section{Research Method}

Thailand's Digital Skills Scenario of the Workforce to Promote Digital Economy Under \& Post COVID-19 Pandemic is a qualitative research method that involve an einterview and desk research focused on the ecosystem of workforces empowerment in Thailand relevant to digital skills to serve the digital economy. The e-Interviews have been made to 45 interviewees who are urban migrant job seekers, fresh graduated students, private sector, business association, and government agencies under the current situation where COVID-19 pandemic and the technologies disruption to shape the new future jobs.

\section{FINDINGS AND DISCUSSION}

The results present as of the research objectives : (1) to study the scenario of workforces under the digital economy affected from COVID-19 pandemic and the digital technology disruption relevant with digital skills in Thailand; (2)to study the scenario of the digital skills relevant to the future jobs skills among all the workforce in Thailand; (3) to study the government's policy relevant digital re-skill and-up-skilling among the workforces for the demanding future jobs and post COVID-19 respectively.

(1) The scenario of workforces affected from COVID-19 pandemic and the technology disruption relevant with digital skills in Thailand;

1.1) Country scenario composed of its general information relevant to digital economy and its effects from technology disruption and COVID-19 pandemic found Thailand 4.0 mission as the economic model driven by innovation, creativity, high-quality, and new technology, employed for boosting the quality of life. This initiative is a steppingstone in the advancement of the country's development focus on rotating the country's labor force into knowledge workers across key economic segments aligned with the 20-year National Digital Economy Masterplan. Industry focus for growth and employment Smart Electronics, Automation and Robotics, Medical \& Wellness Tourism, Digital, and Food for 
the Future. Digital industries are expected to prosper over the coming years. By 2022, 61\% of Thailand's GDP is predicted to be digitalized, due to growth in every industry driven by digital enhancement.

Pandemic in March 2020 expected to recover but remains highly uncertain. Its economy is projected to rebound to 4.0 percent in 2021 and further to 4.7 percent in 2022, underpinned by a recovery in domestic demand and supportive fiscal policy. The lockdowns have resulted in a sudden unemployment rate of up to 16.8 percent of the workforce (5.69 million people are at risk of losing their jobs). Approximately 520,000 new graduates in the 2020 are at risk of no jobs. $54.1 \%$ of workers choose to study online courses to increase skills and competitiveness by either learning how to prepare for a job such as foreign language skills, digital skills, finance and investment.

Most affected are the informal sector to the loss of income resulted to increase from 4.7 to 11 percent of employment in 2020 under the 3-4 waves of pandemic. The National Economic and Social Development Council (NESDC) sounded the alarm on soaring unemployment rates in 2021. One sign is a $9.1 \%$ contraction of GDP for micro and small and medium-sized enterprises (MSMEs); Low and Middle skilled workers, Youth and University Graduate are most high risked. Pandemic resulted in a pattern of businesses shifting from the formal sector to the informal sector affected low skilled, and women workers the most.

1.2) The workers affected from COVID-19 pandemic and technology disruption are (1) the low and middle skilled workers; (2) the youth and university graduate whom are likely to be excluded from the Digital Economy in Thailand as follow;

\section{Group1 : Low and Middle skilled workers (3.9 million at risk)}

Type of business with highest number of unemployment due to the impact of COVID-19 is tourism. Approximately 3.9 million workers in the tourism sector (excluding wholesale and retail sectors) were affected by the impact of the decrease in foreign tourists and a further 2.5 million people affected by decrease of domestic tourism.

Labor in the industrial sector, which was already affected by the trade war prior to the COVID-19 outbreak, continues to be affected due to the decline in domestic and international demand. Around 5.9 million industrial workers, and 1.5 million related sector are expected to be affected.

Employment in service sectors other than tourism will be affected by the pandemic's control measures such as lock-downs. Of the current 10.3 million people employed, around 4.4 million are expected to be affected.

\section{Group 2: Youth and University Graduate (2 millions at risk)}

Approximately 520,000 new graduates in the 2020 academic year are at risk of losing their jobs. In the second half of 2020, the unemployment rate was in the range of 3-4 percent throughout the year which approximately affected 2 million unemployed.

Furthermore, another set of approximately 520,000 new graduates are currently expected to enter the market, in which there may not be enough positions available. (1) The labor market needs only $20 \%$ of the workforce, leaving the remaining 400,000 people permanently unemployed, partly because their bachelor's degrees do not meet the requirements of the employer; and (2) It was mostly found that the youth aged 15-24 years, "Gen Z" group, and non-regular workers (daily workers/sub-contractors) are at the greatest risk of losing their jobs. Currently, around $54.1 \%$ of job seekers choose to study further via online courses to increase skills and competitiveness by either learning how to prepare, to apply for a job, acquiring foreign language skills, or learning about finance and investment.

(2) The scenario of the digital skills among Thai workers relevant to the future jobs skills among all the workforce in Thailand as well as after COVID-19 pandemic found

2.1) Digital skills found the rise of digital infrastructure projects in the country to serve the emerging Jobs analyzed from Linkedin 2020,WEF state the top emerging jobs in Data Analysts \& Scientists, Digital Marketing Specialist, Software and application developer which also aligned with e-Interview found Data Analysts \& Scientists, AI and Machine Learning Specialists, Big Data Specialists, Digital Marketing and Strategy Specialists are topmost. Critical success factors to be successful in the jobs are related to standard hard-skill sets with digital skills embedded. While the e-interview of 36 samples found the most excluded groups are 1) the mid skilled migrant workers and 2) the informal workers with average age range 35-45 years old with Degree and High school accordingly. Their currently skills are the operating skills i.e. System administrator. Windows Office, Internet, Photoshop, Word press, Basic Coding, Internet Computer Network, Website while their demanding for re-skills are Coding, IoT, e- commerce, digital marketing; and 3) the University Graduates average 20-25 years old has moderate digital skills, their demanding digital skills are Digital Designer, Website Designer, Mobile Application Developer, Drone Specialist, SEO designer, Digital Marketer, Digital Copywriter, Programmer, Content Manageras shown in table1. 
Table 1 : Top emerging Jobs analyzed by WEF, Linkedin, and the current interview 2021

\begin{tabular}{|c|c|c|}
\hline $\begin{array}{l}\text { Across industries ranking } \\
\text { Source: World Economic Forum (WEF) }\end{array}$ & $\begin{array}{l}\text { Across industries ranking } \\
\text { Source: Linkedln }\end{array}$ & Source: E-Interview \\
\hline 1. Data Analysts and Scientists & 1. Data Scientist & 1. Digital Marketer \\
\hline 2. Al and Machine Learning Specialists & 2. Back - end Developer & 2. Online marketing \\
\hline 3. Big Data Specialists & 3. Data Engineer & 3. Computer Engineer \\
\hline 4. Digital Marketing and Strategy Specialists & 4. Full Stack Engineer & 4. Graphic Designer \\
\hline 5. Process Automation Specialist & 5. Product Owner & 5. Stock Photographer \\
\hline 6. Business Development Professional & 6. Data Analyst & 6. Video editor \\
\hline 7. Digital Transformation Specialists & 7. User Experience Designer & 7. Website Designer \\
\hline 8. Information Security Analysts & 8. Talent Acquisition Specialist & 8. Mobile Application Developer \\
\hline 9. Software and Applications Developers & 9. Digital Marketing Specialist & 9. Creative \\
\hline 10. Internet of Things Specialists & 10. Front - end Developer & 10. Web Master \\
\hline
\end{tabular}

1.3) Policy to support Digital Skills Post COVID-19 found under 20-year National Digital Economy Masterplan, the government has released massive policies including Digital Economy and Society Development Plan (2017 - 2036) dedicating to develop human capital towards the digital skills by equipping all workers with appropriate knowledge and skills in preparation for a the digital demanding jobs i.e. Ministry of Labor has established DISDA to develop and enhance the digital skills to meet new job demands.

More policy move for digital skilling are the private sector collaboration, including more targeted incentives, could help expand such training to a wider group of workers to help reduce skills gaps across industries. Deepen School-industry Links to Improve Employability of Graduates by driving a formal tripartite mechanism for regular consultation among the government, the industry, and the education institutions for employment, internship, apprenticeship, on-site training .

\section{Policies to empower workforces in Thailand}

1. The National Higher Education, Science, Research and Innovation (NHSO) Ministry of Higher Education, Science, Research and Innovation (TSU)

Grants: Small and medium-sized business grants to innovate and upgrade technology by STTR (Small Business Technology Transfer Research and Innovation)

Support SME to Build Innovation for economic recovery

1.1) Facilitating research and Innovation, access to expert personnel resources and tools and equipment necessary for research and to promote innovations to revitalize road activities economy of SMEs

\section{2) Funding for SMEs (grant)}

2. Higher Education Institutions both public and private, under the Ministry of Education act Providing knowledge in basic skills required to support the reopening of activities in the industrial economy Developing occupational skills necessary for unemployed people to be able to return to work ("Re-skill, Up-skill, and New-skill”)
2.1) Short courses for fresh graduates or for those that will graduate within a "specific skills" career path

2.2) Build entrepreneurs / SMEs to have knowledge and skills in business management and e-commerce or for restoring or restructuring businesses

\section{Ministry of Digital Economy and Society}

\section{1) Training program : "Thais have jobs"}

A project by the Ministry of Digital Economy and Society with a budget of more than 1.99 billion baht to train new graduates who may not have basic digital skills or do not meet the market needs (approximately 50,000 people for 3 months). The project will provide 10,000 Baht per month for project participants. Participants can choose at least 2 of the 4 training courses:

(1) Online Content Creation

(2) Big Data Management

(3) Online Marketing and

(4) Online Commerce.

After the training, job matching is done so that entrepreneurs can find people with skills that match their needs. It is expected that this job matching will be done under the platform "Thais have jobs". Success indicators of the project include 5,000 graduates who were able to progress into becoming digital entrepreneurs, and another 15,000 who were employed in digital business groups of workers replaced by technology or in excess capacity. This project will also further the development of skills that necessary to meet the demands of a post COVID-19 labor market.

\section{United Nations Industrial Development Organization (UNIDO) and Ministry of Industry Capacity Building}

To support SMEs and large enterprises to adopt environmental and climate friendly technologies.

UNIDO is embedded with the Ministry of Industry through a staffing secondment to build Ministry staff capacity on inclusive and sustainable industrial development. The 
agency leverages US\$16.6 million from private and public sources to support SMEs and large enterprises to adopt environmental and climate friendly technologies.

\section{Royal Thai Government (RTG),}

International Labor Organization (ILO), United Nations Development Programme (UNDP), United Nations Environnent Programme (UNEP) United Nations Industrial Development Organization (UNIDO) and National Economic and Social Development Council (NESDC) as shown in table2.

Table 2: List of Digital Skills Partners in Thailand (both International and National)

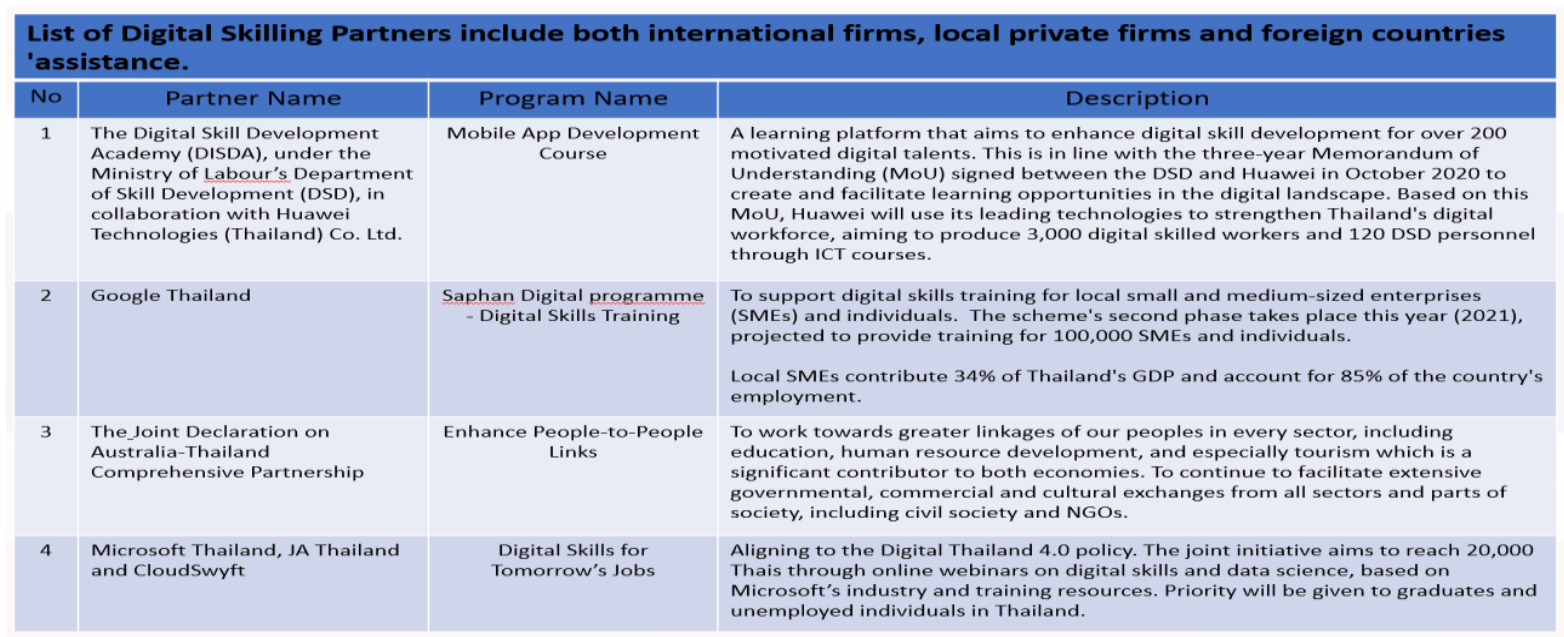

\begin{tabular}{|c|c|c|c|}
\hline No & Partner Name & Program Name & Description \\
\hline 5 & $\begin{array}{l}\text { Microsoft Thailand, } \\
\text { The Ministry of Labor }\end{array}$ & $\begin{array}{l}\text { Mission to upskill } 4 \text { million Thai } \\
\text { workforce nationwide }\end{array}$ & $\begin{array}{l}\text { To upskill } 4 \text { million Thai workforce nationwide, increasing their potential to } \\
\text { reach more employment opportunities and building sustainable economy } \\
\text { through greater digital citizenship. Microsoft to provide necessary digital } \\
\text { skills and learning resources including Microsoft Teams to connect people } \\
\text { together through Department of Skill Development under Ministry of } \\
\text { Labor and to help people in all career fields to achieve more, builds on the } \\
\text { company's efforts in its Global Skills Initiative }\end{array}$ \\
\hline 6 & $\begin{array}{l}\text { Thailand's Digital } \\
\text { Economy Promotion } \\
\text { Agency (DEPA) }\end{array}$ & $\begin{array}{l}\text { Reskilling the workforce - continue } \\
\text { developing the digital curriculum for } \\
\text { primary schools, high schools and } \\
\text { universities across the country }\end{array}$ & $\begin{array}{l}\text { YouTube to equip citizens with digital skills. The Thai Skill channel shares } \\
\text { tips for small local businesses, including how to buy on international e- } \\
\text { commerce sites and calculate taxes online. Basic digital skills will be } \\
\text { necessary to carry Thailand into a tech-powered economy to learn its } \\
\text { priorities for reskilling the workforce. }\end{array}$ \\
\hline 7 & $\begin{array}{l}\text { The Ministry of Labor - } \\
\text { the Digital Skill } \\
\text { Development Academy } \\
\text { (DISDA), }\end{array}$ & Building Thailand Digital Workforce & $\begin{array}{l}\text { The Ministry of Labor launched the Digital Skill Development Academy } \\
\text { (DISDA), to oversee digital skill development for the workforce; and a new } \\
\text { DSD application in collaboration with the leading technology company to } \\
\text { build capable workforce for the digital economy. }\end{array}$ \\
\hline
\end{tabular}

Industrial Sector - ICT, and Service sub sector - Travel and Tourism are the two major industries that will be promoted in the Post-COVID-19 in Thailand

Thailand has made remarkable progress in social and economic development, moving from a low-income to an upper middle-income country in less than a generation. As such, Thailand has been a widely cited development success story, with sustained strong growth and impressive poverty reduction. Gross Domestic Product in Q4/2020 decreased by $4.2 \%$, improving from a fall of $6.4 \%$ in $\mathrm{Q} 3 / 2020$, agricultural production increased by $0.9 \%$, The tourism sector, which accounts for about a fifth of GDP and 20 percent of employment, has been especially affected by the cessation of tourist travel.

\section{Industrial Sector}

Industry Sector contributed $36.2 \%$ of GDP and employed $28 \%$ of the total workforce in 2020.

\section{Agriculture Sector}

Agriculture sector contributed $8.2 \%$ of GDP and employed $22.52 \%$ of the total workforce in 2020 .

\section{Service Sector}

Service sector contributed $55.6 \%$ of GDP and employed 46.33 percent of the total workforce in 2020.

\section{Industrial Sub Sector : ICT}

Thailand aspire to break out of the middle-income trap by moving towards technology- and knowledge-intensive 
industries. They face similar challenges in equipping their workforces with the necessary science and engineering skills and in broadening the appeal of technical education to a wider segment of the student population. The Thai workforce enjoys near full employment but there remains substantial underemployment in the agriculture and the informal sectors. Thailand relies on foreign workers to carry out low-skilled and unskilled work. Thailand must also cope with a fast ageing population.

\section{Service Sub Sector : Travel and Tourism}

Tourism generally accounts for $12 \%$ of gross domestic product (GDP) and foreign visitor numbers fell $83 \%$ to 6.7 million in 2020 , when the economy likely contracted $6.5 \%$. Thailand's finance ministry slashed its 2021 economic growth forecast to $2.8 \%$, from $4.5 \%$ growth projected earlier, after fresh waves of COVID-19 cases in the Southeast Asian nation and other countries hit tourism. Thailand expects the tourism-reliant country to receive 5 million foreign tourists in 2021, down $25 \%$ from last year and compared with 8 million predicted earlier.

\section{Challenges of industry adoption}

The nation's labor shortages involve both quantity and quality- not enough people, low skills, calls for three types of measures;

1. Revamp hiring by improving recruitment networks and processes, beefing up pay and benefits.

2. Improve worker productivity by increasing the use of machinery and technology, redesigning processes, and enhancing training.

3. Increase staff retention by improving job satisfaction and engagement.

Industry needs to hire enough new recruits, give them the right tools and skills, bridging the gap means staying both fully staffed and highly efficiency. the industry could be transformed. digital technologies have created the market opportunity for the industries and further to greatly improve productivity. however, the labor market disruption could be significant given the advancements in digital technology related that can increasingly automate some of these services. significant ramp up of on-the-job training, particularly for analytical skills - the fact is all new trainings related to technology will need to be delivered on-the-job.

Respond from the e-interview of Thai government agencies in any support provision

\section{1) DEPA Digital Manpower Fund}

DEPA has supported the digital skill development, both upskilling and reskilling, through "DEPA Digital Manpower Fund." it is granted to individuals, youths, students, unemployed, government officials, government agencies, public and private institutes. the measure focuses on improving people's digital skills in high demand such as cybersecurity, programming, data analytics, coding, and cloud computing, etc. through both offline and online learning scheme.

\section{2) Digital Economy and Society Development Funds}

Digital Economy and Society Development Fund of office of the National Digital Economy and Society Commission was established to finance digital development including the implementations and projects related to digital technology education for youth, the elderly and the workforce.

\section{3) Skill Development Fund under Department of Skill} Development

The fund aims to promote skill development. business operators can loan money form the fund for financing programs or initiatives involving skill development and training.

\section{4) Student Loan Fund}

The objective of the fund is to expand accessibility of students from low-income families to obtain higher educational degrees.

\section{5) Equitable Education Fund}

The fund aims to financially support disadvantaged children by covering their expenses until they complete their basic education.

Government policies: Gaps of Skill Mismatch, Unplanned Manpower blockage the beneficiary from accelerating digital skilling opportunity

\section{TVET Skill Mismatch}

There is strong alignment between the skills that training institutions believe will be particularly important due to the new technology and the perceptions of employers. However, some training institutions may be struggling to keep pace with the rate of change in skills demand. There also seems to be a severe misalignment between training institutions' expectation of graduate preparedness for work, and employers' expectations about the skills graduates require to perform well in entry-level roles, as well as their general and job-specific skills. aligning curricula with actual industry needs is one of the most important but often the most challenging components of an effective training and education sector. It relies on frequent updating and close communication with industry, given the speed of change in new technology in the workplace. Regular curriculum reviews are therefore critical for keeping pace with the skill changes. Weakness in stem and technical and vocational education and training (TVET) program. The private sector, be it large corporates or industries trying to meet their own skills needs, or general private educational services providers, can respond more quickly, with greater agility and flexibility, to skills demands. In contrast, the public sector tends to move slowly to meet emerging skills demands. The public sector could play an 
effective role coordinating the skills development efforts of the private sector and other stakeholders.

\section{National policy responses}

Thailand, faces two skills gaps' challenges. There is uneven quality and a shortage of skilled workers, and also uneven quantity which is especially severe in science, technology . Surveys consistently find that Thai workers lack English language proficiency, IT and other soft skills. It is recognized that skills gaps will likely pose hurdles for industries that the Thai government is trying to promote as key growth drivers including tourism, agriculture and manufacturing sectors such as automotive, biochemical, electronics and food processing.

Such shortcomings are also seen as a potential obstacle for the digital economy, which the government hopes to develop as a new pillar to raise competitiveness and productivity. Government can also play a significant role in providing information about skills gaps in key industries. Closer government-private sector collaboration, including more targeted incentives, could help expand such training to a wider group of workers to help reduce skills gaps across industries.

\section{Respond from the e-interview to Thai government agencies}

1) Shortage of skilled workers - many organizations are struggling to hire people with the right skills. this is because most of the new graduates do not have an internship or relevant work experience. also, the recent graduates tend to work in a field different from their degrees.

2) Outdated curriculum - Secondary and Tertiary curriculums are not in line with the current job market that requires digital skills. students still have to learn things that are already obsolete or irrelevant to the market demands because of inflexible curriculums.

3) Work permit restrictions - many organizations are unable to employ digital manpower from neighboring countries or abroad due to work permit restrictions and complication of immigration procedures.

The Government Plans to solve the problem of skill mismatch and skill shortage facing all the target industries by

\section{Provide stronger incentives for Private sector-led skill training programs}

the government should explore more creative and differentiated incentives to encourage different modes of skills training by the private sector, either working on its own or in collaboration with the public sector. experiences of neighboring countries in leveraging on the goodwill and expertise of the MNCS and their host governments in setting up various technical training institutions could be used as references. while most of these private sector- led trainings are undertaken by MNCS and large domestic corporates, efforts should be made to spread the benefits of the trainings to workers outside the company and the industry.

\section{Strengthen training of soft skills and English language}

the government should provide more incentives to the noncorporate private educational service providers to work with the formal educational sector, to play a larger role in the teaching of soft skills and English language. the openness of the Thai economy and Thai culture makes for easy participation of foreign skill trainers which should be further exploited.

3. Give the private sector a bigger role in meeting the skills challenge

the different roles between the public and private sectors in skills training provision should be recalibrated, to give the latter a much bigger role. a lighter regulatory approach on education and skills training including deregulation of the education sector could be considered. the government should act as an effective facilitator using a mix of policy support, regulatory support, and other incentives. there is also an urgent need to strengthen the tripartite cooperation among the government, industry and the educational and training institutions to coordinate the skills training efforts by various stakeholders. the government's role as a facilitator could encompass the following:

3.1) Provide a consistent framework for private sector training at both the national and the local level.

3.2) Help the private sector companies tap into the resources of the educational institutions to address various industry-school gap issues.

3.3) Design different incentives to promote industry- and company-level training initiatives, and to broaden the reach of such training beyond specific companies or industries.

3.4) Provide incentives for multinational corporations (MNCS) and large corporations to involve small and mediumsized enterprises (SMES) in their training schemes.

\section{Provide a clear roadmap to meet skills challenges}

The government should work with the private sector and the educational institutions to provide a comprehensive roadmap for skills development that is consistent with, and targeted at supporting its growth and development vision for the economy. Among other details, the roadmap should provide a credible projection of supply and demand for critical skills needed in key growth industries, spell out clear roles for the main stakeholders and provide guidance on possible collaboration among them. Where resources permit, consideration could be given to setting up a one-stop service agency, with sufficient autonomy and authority, to manage the various facets of the skills challenges. 
Respond from the e-interview of Private and Industries agencies

Thailand, companies upskill their employees to embrace digitalization and prepare them for tech-enabled roles using funding from tax incentive or use their own in-house budget.

Thai workforce enjoys near full employment but there remains substantial under employment in the agriculture and the informal sectors. Thailand still rely on foreign workers to carry out low-skilled and unskilled work. Thailand must also cope with a fast-ageing population seems being one among the fastest countries in ASEAN. Disruptive technology threatens to render jobs obsolete in many industries, including those in information and communications technology (ICT), tourism, electronics manufacturing, and financial services. Managing disruptive technologies requires a paradigm shift in the thinking of policy makers, employers, and employees alike. policy makers and employers must find new ways to develop a skilled but flexible workforce that accepts the need for continuous and lifelong learning.

\section{1) Use In-House resources to meet their own shortages via Apprenticeship program}

Organizations usually believe in developing their employees, especially by on-the-job training that can build firm-specific qualifications. human resource development skill is seen as an essential tool to help an organization achieve its objectives by providing effective and necessary training to employees; thus, training is truly seen as a continuous investment which should be done systematically from training needs analysis until training evaluation. In addition, the activities in the progressive model are not only limited to training, but they include other types of activities that can continuously develop employees. Large private sector corporations, including multinational corporations provide inhouse and/or offer apprenticeship programs. Much of the skills training in the corporate and industry is done in-house. However, the private sector's potential in meeting the skills challenges has not been fully capitalized, partly because lack of a targeted government policy to incentivize such training.

\section{2) Use business Tax incentives}

Tax incentives offer to entrepreneurs in order to promote a more competitive tech-led innovation environment in Thailand. Digital transformation alone can be extremely costly. Government should offer a special tax exemption to any businesses that invest in activities involving innovation. This is to encourage businesses to continuously invest in innovation to improve their operational efficiency and productivity, which in turn promotes the growth of the company and country as a whole. Thailand has seen some initial movements.

\section{CONCLUSION}

Thailand's Digital Skills Scenario of the Workforce to Promote Digital Economy Under \& Post COVID-19 Pandemic and technology disruption's contexts as follow;

1. The scenario of workforces relevant with digital literacy and digital skills among all the marginal workers in Thailand found affected by the pandemic as well as technology disruption resulted in a pattern of businesses shifting from the formal sector to the informal affected low skilled. The Future of work has already arrived for a large majority of the online white-collar workforce. Eighty-four percent of employers are set to rapidly digitalize working processes, including a significant expansion of remote work with its trend to change $44 \%$ of their workforce to operate remotely.

2. The scenario of the digital skills relevant to the current and the future jobs skills among all the marginal workers found the top emerging jobs are data analysts \& data scientists, digital marketing specialist, software and application developer, youtubers and Start Ups. all kinds of administrative jobs, secretaries, accounting, bookkeeping, payroll clerk, HR would be declining.

Most of the marginal workers have low-mid digital skills such as Microsoft Office, digital marketing, photoshop, social media, content creating, video editing. workers are looking forward to reskills in all related digital skills from fundamental to mid and high skills such as data analytic, data science, software development, web development, cybersecurity, AI and programing are necessary profiles that one must have in-depth knowledge in order to attract all the demanding jobs.

3. The government's policy relevant to support any digital reskill-upskilling among the workforces including the marginal workers to serve well with all demanding skills of the future jobs found similar in 1) accelerate workforce digital competency by partnering with private and industry sectors through TVET training system; 2) working with industry leader to revamp national curriculums via Digital Learning Pathway and emerging skillsets. The PPP strategy must be used for knowledge transfer and support to building Digital Ecosystem.

\section{REFERENCES}

[1] TAN, Kim Song and TANG, James T. H. (2016). New skills at work: Managing skills challenges in ASEAN-5. (2016). Research Collection School Of Economics. Available at: https://ink.library.smu.edu.sg/soe_research/1891

[2] The Future of Jobs Report 2020. (2020). World Economic Forum Platform for Shaping the Future of Jobs. Available at: https://ink.library.smu.edu.sg/soe_research/1891

[3] BOI (Board of Investment). 2019. Digital, Creative, and Startup Ecosystem September 2019 : Thailand's Digital Economy https://www.boi.go.th/index.php?page=business_opportunities_det ail\&topic_id=117530\#: :text=Thailand\%20is\%20working\%20to $\% 20$ drive, a\%20cutting\%2Dedge\%20economic\%20powerhouse.\&t 
ext=The $\% 20$ Digital $\% 20$ Economy $\% 20$ is $\% 20$ expected,to $\% 20$ Thail and's\%20GDP\%20by $\% 202027$.

[4] Ministry of Higher Education, Science, Research and Innovation. (2019). Startup Ecosystem https://www.boi.go.th/upload/content/BOI_Digital_Economy_Bro chure.pdf

[5] Ministry of Digital Economy and Society (MDES). (2019). Digital Infrastructure

https://www.boi.go.th/upload/content/BOI_Digital_Economy_Bro chure.pdf

[6] Baharin Abu, Othman Md Johan, Syed Mohd Shafiq Syed Mansor \& Haliza Jaafar. (2007) Kepelbagaian gaya pembelajaran dan kemahiran belajar pelajar universiti di Fakulti Pendidikan, Universiti Teknologi Malaysia http://eprints.utm.my/3680/1/7881.pdf. Diperoleh pada 15 Julai 2011.

[7] Dunn, R \& Dunn K. (1978). Teaching Students Through Their Individual learning Styles: A Practical Approach. Virginia: Reston Publishing Company, Inc.

[8] Dunn, R. (1984). Theory into Practice. Matching Teaching \& Learning Styles. 23:1, 10-19. http://www.jstor.org/stable/1476733. Diperoleh pada Oktober 11, 2011.

[9] Kementerian Pelajaran Malaysia. (1997). Akta Pendidikan 1996.

[10] _. (2012). Laporan Awal Pelan Pembangunan Pendidikan Malaysia 2013-2025.

[11] Lerner, J. W. (2003). Learning Disabilities: Theories, Diagnosis, and Teaching Strategies. Edisi ke-9. Boston: Houghton Mifflin Company.

[12] Morton, J. (2011). Attention Deficit Disorder and Sound Therapy. Diperoleh pada Januari 28, 2011. http://www.Soundtherapyperth.com/benefit/add.php. 